\title{
A Internet no desvendar da ciência em casa
}

\author{
VASCO SÉRGIO CORREIA FREITAS SILVA*
}

\section{Resumo}

A importância da execução de experiências exploratórias simples (com recurso a materiais de uso quotidiano) na contextualização da ciência com a vida real tem sido amplamente reconhecida por professores e cientistas. Tendo em conta o fraco interesse dos portugueses pelas ciências Química e Física, a divulgação na Internet de actividades práticas envolvendo estas ciências pode ser utilizada como um complemento aos meios tradicionais de ensino. Neste contexto, esta comunicação apresenta o sítio de Internet "Ciência em Casa" (http://cienciaemcasa.cienciaviva.pt) como fonte de conteúdos científicos com real valor pedagógico para a divulgação de actividades experimentais simples no âmbito da Química e Física.

\section{Introdução}

O conhecimento do cidadão comum em ciências é comprovadamente insuficiente e, cada vez mais, os jovens não demonstram grande interesse pela ciência, fundamentalmente pela Química e Física [1]. Estas ciências foram sempre definidas como ciências sofisticadas, próprias de cientistas que trabalham com sistemas caros e complicados. Em Portugal, os locais assumidos como próprios para a ciência acontecer são desde sempre as escolas, universidades e centros de ciência.

De maneira a despertar o interesse na população portuguesa pela ciência, tem vindo a verificar-se um aumento do investimento nos espaços vocacionados para o ensino e aprendizagem desta: escolas e centros de ciência. As escolas passaram a ser equipadas com material pedagógico e científico para facilitar o trabalho dos professores no ensino das ciências. Igualmente, os programas das disciplinas apresentam diversas propostas de actividades práticas interessantes para serem implementadas na sala de aula [1]. Nas aulas, o professor investe cada vez mais tempo em conteúdos experimentais que permitem aos alunos o contacto directo com os conceitos leccionados. Relativamente aos centros de ciência, em Portugal tem sido realizado um investimento considerável em centros "Ciência Viva" que têm desempenhado um papel importante na divulgação da ciência. Para além de apresentarem diversas actividades práticas num ambiente informal, organizam igualmente outras actividades fora dos recintos de exposição. $\mathrm{Na}$ actualidade, Portugal conta com cinco centros "Ciência Viva" e no futuro está prevista a abertura de mais nove [2].

No entanto, em geral, o cidadão comum ainda desconhece o facto da ciência estar sempre presente na vida real. Por exemplo, a Química e a Física são ciências que podem ser facilmente experimentadas em casa, com materiais pouco sofisticados ou de uso corrente. Como ciências especialmente ligadas ao dia-a-dia, estas proporcionam os ingredientes indispensáveis ao desenrolar de um ambiente ideal de ensino-aprendi- zagem [3]. 0 desvendar destas ciências em casa, a partir de actividades práticas, desperta curiosidade, motivação e interesse pela aprendizagem dos fenómenos físico-químicos do quotidiano. Actualmente existem no mercado diversos livros de actividades exploratórias simples que podem ser implementadas com materiais de uso corrente [4-10].

Nos últimos anos, as inovações tecnológicas têm vindo a possibilitar diversos meios alternativos de ensino e aprendizagem [11]. Meios pedagógicos não impressos, incluindo CD-ROM, cassetes vídeo e, principalmente, Internet, possibilitam formas interactivas de divulgação da ciência. Através de conteúdos multimédia, esta pode ser apresentada de uma forma mais completa e atraente em comparação com o texto ou discurso convencional [2]. A modo de exemplo, a Internet pode combinar texto, audio, ilustrações e elementos dinâmicos como, por exemplo, vídeos e animações. Igualmente, em contraste com as escolas e os centros de ciência, os conteúdos científicos na Internet podem ser consultados por qualquer pessoa, a 
qualquer hora, sem restrição de horários. No entanto, actualmente, em Portugal ainda existe uma preocupante escassez de conteúdos educativos na Internet.

Com o objectivo de tornar a Internet num meio com real valor pedagógico para o ensino das ciências Química e Física, o sítio de Internet "Ciência em Casa" (http://cienciaemcasa.cienciaviva.pt) surge como um complemento aos meios tradicionais de ensino da ciência em Portugal [12]. A principal vertente do sítio em questão é a divulgação de experiências simples que ilustram conceitos científicos importantes como, por exemplo, a pressão e a densidade.

\section{Desvendar a ciência em casa}

O desconhecimento do facto de todo 0 conhecimento científico ter as suas raízes em observaçōes simples pela maior parte das pessoas, faz com que estas observem os acontecimentos do seu dia-a-dia sem qualquer base científica [5]. A aventura da ciência acontece praticamente durante todo o dia, mas a maioria não a sabe desvendar e entender. Muitas pessoas desconhessem que a maior parte dos conceitos científicos podem ser ilustrados/verificados com materias de uso corrente e que, desta forma, a ciência para além de acontecer nas escolas e nos centros de ciência pode acontecer em casa, com sistemas fáceis de implementar.

A Química e a Física são excelentes exemplos de ciências intimamente ligadas à vida real, estando presentes praticamente em todas as actividades humanas [3]. Diversas actividades quotidianas que envolvem diferentes materiais, formas, suas composições, estruturas, propriedades e reacções podem facilmente ilustrar estas ciências. O contacto intimo (tocar, sentir, cheirar, ver, etc.) com a ciência aproxima os experimentadores dos fenómenos em estudo, facilitando a sua compreesāo através de analogias com o dia-a-dia [13]. Após a experimentação e verificação dos conceitos científicos, o experimentador passa a olhar o mundo de maneira diferente, a ver coisas que nunca viu e, eventualmente, a fazer coisas que nunca fez porque achava que não era capaz [14].

Para além disso, a experimentação directa da ciência em casa envolve igualmente actos individuais de preparação $e$ execução da actividade prática. $\mathrm{Na}$ actualidade, a maioria das actividades experimentais nas escolas envolvem materiais e protocolos previamente escolhidos e organizados pelo professor e o objectivo principal do aluno é a obtenção da resposta certa [13]. Em contraste, a experimentação da ciência em casa pode ser encarada como investigativa, onde o experimentador pode testar facilmente diversas teorias implementando sistemas de raiz. Desta forma, o trabalho experimental autónomo e de descoberta pode levar ao desenvolvimento de capacidades para a compreensão da natureza prática do trabaIho científico. Mesmo tratando-se de actividades fáceis de implementar, demonstrativas e qualitativas, a criatividade e inovação do experimentador estão sempre presentes durante a sua execução, visto que os sistemas de experimentação não são restritos a uma determinada instalação. Por exemplo, o experimentador pode alterar o sistema para tornar o fenómeno mais perceptível, ou até, testar diferentes materiais ou aproximações.

Igualmente, a introdução de certos conceitos científicos importantes a partir de experiências lúdicas realizadas em casa, pode satisfazer as expectativas e curiosidades iniciais do experimentador pela Química ou Física. Logo à partida, este apresenta uma natural curiosidade e uma certa sensação de "suspense" pelo desenrolar e desenlace da actividade [3]. Com o envolvimento e participação activa do experimentador, as experiências tornam-se pessoais, motivadoras e interessantes. Deste modo, as expectativas iniciais pela Química e Física não saem defraudadas. Este facto contrasta com a desilusão, desinteresse e afastamento que o aluno sente quando nas aulas convencionais é realizada uma sistemática abordagem teórica de matérias fastidiosas e não é feita a contextualização do conceito científico com o dia-a-dia [3].

$\mathrm{Na}$ actualidade, em Portugal, existem diversos livros de ciência divertida que podem ser adquiridos nas livrarias [4-10]. A maior parte dos livros apresentam diversas actividades experimentais exploratórias interessantes para todos os curiosos em ciência. No entanto, na maior parte das vezes o público alvo dos livros em questão são alunos do ensino básico e secundário. Os materiais envolvidos são geralmente de uso quotidiano e de fácil aquisição. Os diferentes livros primam pela abordagem simples dos conceitos teóricos e pela estratégia de tornar a ciência divertida e atraente. Estes apresentam as actividades experimentais estruturadas segundo temas bem definidos, tornando por isso a sua consulta fácil e rápida. No entanto, as potencialidades pedagógicas deste meio de ensino ainda não estão totalmente exploradas, visto que, sendo um meio de divulgação impresso, este apresenta a particularidade de proporcionar pouca interactividade (elevada energia de activação), impossibilidade de aprofundamento de conhecimentos e de ser difícil o contacto leitor/autor para a discussāo de aspectos relacionados com as actividades ou fenómenos envolvidos.

\section{Internet versus livros na divulgação da ciência}

$\mathrm{O}$ aumento da popularidade da Internet e das tecnologias multimédia está a resultar no desenvolvimento de novas estratégias para o ensino e aprendizagem da ciência [15]. A Internet como meio de divulgação científica apresenta diversas vantagens relativamente aos livros. Primeiro, os materiais impressos requerem períodos de desenvolvimento longos, mas quando publicados sāo estáticos e rapidamente ultrapassados [16]. Este facto contrasta com a dinâmica associada à Internet. Qualquer sítio pode ser actualizado em fracções de segundo e manter o leitor sempre interessado por novos conteúdos.

Segundo, na tentativa de apresentar o máximo de informação e de abranger a maior audiência possível, os autores e 
editores criam textos generalistas que os leitores têm de estudar exaustivamente para retirar o que thes interessa [16]. Ao nível da Internet, os conteúdos podem ser melhor distribuídos e seleccionados para cada determinado tipo de leitor alvo. A selectividade do conteúdo apresentado pode ser muito maior.

A terceira limitação dos conteúdos impressos é o facto de estarem limitados a formatos bidimensionais [16]. Em contraste, a Internet disponibiliza uma grande variedade de conteúdos visuais e auditivos, possibilitando aos visitantes a aprendizagem dos conceitos de uma forma mais concreta e motivante. Diversas formas de aprendizagem podem ser estimuladas através da utilização de texto associado a conteúdos audio, visuais, gráficos e elementos dinâmicos [11]. Os leitores podem assim aprender os fenómenos científicos de uma maneira abstracta e ver a sua aplicação concreta através de animações ou vídeos.

Por fim, a quarta e mais importante limitação dos conteúdos impressos é a sua falta de interactividade [16]. 0 contacto autor/leitor é complicado e a discussão ou aprofundamento de assuntos relacionados com a publicação é praticamente impossível. Em contraste, a Internet possibilita a ligação a informaçōes adicionais disponiveis noutros sítios de Internet, discussão em forúns e clarificação de dúvidas directamente com o autor. Ainda mais importante é o facto do próprio visitante poder participar no conteúdo do sítio [16].

\section{O sítio "Ciência em Casa"}

O sítio "Ciência em Casa" foi publicado na Internet no ano de 1999 por um estudante de Engenharia Química (agora estudante de doutoramento) no Departamento de Engenharia Química da Faculdade de Engenharia da Universidade do Porto [12].

O principal objectivo deste sítio é o de divulgar a Química e Física de uma forma simples e divertida, tirando partido das potencialidades que a Internet disponibiliza. Em contraste com os livros de ciência divertida existentes no mercado, o conteúdo do sítio em questāo aposta na interactividade, design gráfico atraente, actualização permanente, utilização de conteúdos multimédia e, principalmente, tornar o sítio do visitante e não somente do autor. 0 público alvo do sítio são professores, alunos e pessoas leigas que tenham curiosidade acerca das ciências Química e Física que acontecem no dia-a-dia [12].

O coração do sítio são as experiências científicas que podem ser executadas em casa com materiais de fácil aquisição [12]. Todas as experiências propostas envolvem baixos níveis de perigosidade e custo. No presente, o "Ciência em Casa" apresenta 49 experiências, abordando diversos temas, desde os estados físicos da matéria até à electroquímica.

Para além de propor demonstrações científicas simples, o sítio "Ciência em Casa" contém igualmente outros conteúdos que têm por objectivo complementar o coração do sítio (experiências). Os conteúdos com maior relevância são o concurso bimestral "Ciência em Casa" e o espaço "Eureka!".

O concurso "Ciência em Casa" tem como objectivo cultivar a participação dos visitantes no conteúdo do sítio, através da aplicação dos seus conhecimentos científicos para resolver desafios lançados pelo autor. Até ao momento todos os concurso publicados obtiveram respostas, sendo por vezes complicado escolher a vencedora. É de notar que o concurso não tem qualquer prémio monetário ou material. Ao vencedor do concurso somente é assegurada a publicação da resposta numa página específica para o efeito com o seu nome.

Por sua vez, o espaço "Eureka!" é reservado às dúvidas que os visitantes podem colocar no sítio para serem respondidas por outros visitantes. Este espaço funciona à semelhança da famosa secção "The last word" do New Scientist [17].

Relativamente a outros conteúdos adicionais, estes apresentam informação útil para o cientista caseiro. Neste grupo estão inseridas as secções do glossário de definições científicas, "Questionarium" onde o visitante pode examinar os seus conhecimentos e, entre outros, as regras de segurança para a execução das actividades experimentais.

Recentemente, o sítio "Ciência em Casa" passou a ser alojado no directório do "Ciência Viva" (http://cienciaemcasa .cienciaviva.pt) e, igualmente, foi publicada a versão em inglês.

\section{Conclusões}

Para o futuro de Portugal é prioritário que a sociedade desperte para a ciência. É essencial que, pelo menos, as novas gerações adquiram uma cultura científica e tecnológica mais sólida e com mais significado nas suas vidas.

Funcionando como um complemento educativo, a realização de actividades experimentais simples em casa pode tornar a ciência mais interessante e não defraudar o interesse natural das pessoas pela Química ou Física. As experiências designadas por exploratórias (com recurso a material de uso quotidiano), rápidas e qualitativas permitem a experimentação directa e a contextualização dos fenómenos científicos, aproximando desta forma os experimentadores da sua compreensão.

Utilizando as potencialidades da Internet para a divulgação da ciência, o "Ciência em Casa" surge como uma fonte de conteúdos pedagógicos úteis para professores, alunos e curiosos. Neste sítio, os visitantes podem consultar diversas demonstrações experimentais simples que ilustram qualitativamente conceitos científicos importantes. Para além disso, o "Ciência em Casa" apresenta conteúdo adicional que realça o aspecto lúdico e divertido das ciências Química e Física.

\section{Agradecimentos}

Agradeço ao claustro de professores do Departamento de Engenharia Química da Faculdade de Engenharia da Universidade do Porto pela formação científica e pessoal que me transmitiram. 
Igualmente, agradeço ao "Ciência Viva" o apoio permanente na divulgação do "Ciência em Casa" e o facto de disponibilizarem espaço no servidor para o seu alojamento.

Agradeço ao Professor Adélio Mendes pela sua amizade e orientação. Por fim, agradeço ao Professor Duarte Costa Pereira pelo incentivo para a publicação da presente comunicação.

Bibliografia

[1] Galvão, C., "Todos queremos um ensino das ciências melhor", Química (Boletim da Sociedade Portuguesa de Química), 84 , 2002.

[2] http://www.cienciaviva.pt - Ciência Viva.
[3] Dias, J., "O ensino experimental em Química", Comunicar Ciência, 1, 1998.

[4] Ehrlich, R., "Virar o mundo do avesso", Colecção Aprender, Fazer Ciência, Gradiva, 1992.

[5] Bohren, C. F., "Nuvens numa Caneca de Cerveja - Experiências simples em física atmosférica", Colecção Aprender, Fazer Ciência, Gradiva, 1996.

[6] VanCleave, J., "Química para Jovens", Publicações Dom Quixote, 1998.

[7] Hann, J., "Como funciona a Ciência", Selecções Reader's Digest, 1991

[8] Walker, J., "O Grande Circo da Física", 2. ${ }^{a}$ edição, Colecção Aprender, Fazer Ciência, Gradiva, 2001.

[9] VanCleave, J., "Física para Jovens", 2. ${ }^{2}$ edição, Publicações Dom Quixote, 2000.

[10] Fiolhais, C., "Física Divertida", Colecção Aprender, Fazer Ciência, Gradiva, 1999.

[11] Bates, T., 'Teaching, learning and the impact of multimedia technologies", Educause, September/October, 2000.
[12] Silva, V., 'Sítio 'Ciência em Casa' - Tecnologias da informação aplicadas à divulgação das ciências Química e Física", Ingenium (Revista da Ordem dos Engenheiros), $2^{\circ}$ série, 76, Junho 2003

[13] Almeira, A., "Papel do trabalho experimental na educação das ciências", Comunicar Ciência, 1, 1998.

[14] Lourenço, F., "Que ganhamos hoje em levar os nossos alunos a um museu?", Comunicar Ciência, 3, 1998.

[15] Bollentin, W. R., "Can information technology improve education?", Educom, 33, 1, 1998.

[16] Marion., A. e Hacking, E. H., "Educational Publishing and the World Wide Web", Journal of Interactive Media in Education, 98, 2, 1998

[17] New Scientist, "Os Porquês dos Quês", Colecção Aprender, Fazer Ciência, Gradiva, 2001.

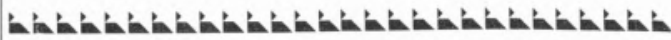 \\ - APCER \\ Certificado de Conformidade \\ de Conformida \\ 96/CEP.410 \\ A Associaçầo Portuguesa de Certificaçẫo (APCER) certifica que o sistema da qualidade da \\ SOQUIMICA - SOCIEDADE DE REPRESENTACCÕES DE QUIMICA, LDA. \\ Rua Coronel Santos Pedroso, 15 \\ PORTUGAL \\ Implementado na comercializaçăo, manutençăo e calibraçào de equipamentos de laboratónio, cumpre os requisitos da \\ NP EN ISO 9002:1995 \\ Sistemas da Qualidade. Modelo de garantia da qualidade na produção, instalą̧ẵo e assistência após-venda \\ O presente certificado é emitido no ảmbito do Sistema Português da Qualidade.

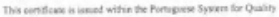 \\ $\begin{array}{lll}2002-06-17 & \end{array}$ \\ $\lim _{i j}$ \\ Luis Fonstce

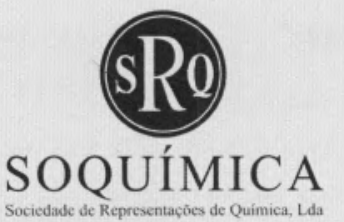

R. Coronel Santos Pedroso 15 - 1500-207 Lisboa Tel 217165160 . Fax 217165169 R. 5 de Outubro $269 \cdot 4100$ - 175 Porto Tel 226093069 . Fax 226000834 E-mail: soquimica@mail.telepac.pt. 